\title{
Profiling a Decade of Information Systems Frontiers' Research
}

\author{
Yogesh K. Dwivedi ${ }^{1}$ \\ Information Systems \& e-Business Group \\ School of Business \& Economics, Swansea University \\ Swansea, UK \\ Email: ykdwivedi@gmail.com \\ Banita Lal \\ Information Management and Systems Group \\ Nottingham Business School, Nottingham Trent University \\ Nottingham, UK \\ Email: banita.lal@ntu.ac.uk \\ Navonil Mustafee \\ Warwick Business School, University of Warwick \\ Coventry, Warwickshire, UK \\ Email: navonil.mustafee@gmail.com \\ Michael D. Williams \\ Information Systems \& e-Business Group \\ School of Business \& Economics, Swansea University \\ Swansea, UK \\ Email: m.d.williams@swansea.ac.uk
}

\begin{abstract}
This article analyses the first ten years of research published in the Information Systems Frontiers (ISF) from 1999 to 2008. The analysis of the published material includes examining variables such as most productive authors, citation analysis, universities associated with the most publications, geographic diversity, authors' backgrounds and research methods. The keyword analysis suggests that $I S F$ research has evolved from establishing concepts and domain of information systems (IS), technology and management to contemporary issues such as outsourcing, web services and security. The analysis presented in this paper has identified intellectually significant studies that have contributed to the development and accumulation of intellectual wealth of $I S F$. The analysis has also identified authors published in other journals whose work largely shaped and guided the researchers published in ISF. This research has implications for researchers, journal editors, and research institutions.
\end{abstract}

Keywords: Information Systems Frontiers (ISF), IS Research, Meta-Analysis, Research Method, Research Profile

\footnotetext{
${ }^{1}$ Corresponding Author: Phone - +441792602340; Fax - +441792295626
} 


\section{Introduction}

Information Systems Frontiers (ISF) is a high-ranking research journal, and a premier journal focusing on the frontiers of IS. Within a short period of time $I S F$ has emerged as a quality outlet for publishing IS research in all three regions of the Association of Information Systems (AIS). For example, The Australian Council of Professors and Heads of Information Systems (ACPHIS) have listed ISF with other high-quality journals in the 'A' Class category ${ }^{2}$ (also see Clarke 2008). Similarly, the UK's Association of Business School's Journal Ranking has included ISF within the list of high-quality IS outlets ${ }^{3}$.

Such recognition within a short period of time was attained through ISF's unique editorial focus, and the composition of its advisory and executive board. As described on the homepage of the journal, Information Systems Frontiers (ISF) aims to provide a common forum of dissemination of the frontline industrial developments of substantial academic value and pioneering academic research of significant practical impact (ISF homepage ${ }^{4}$ ). From the onset, $I S F$ has had a multidisciplinary approach which draws from both well-established fields such as computer science, telecommunications, operations research, economics, and cognitive sciences and the emerging areas which include enterprise modeling and integration, object/web technologies, information economics, IT integrated manufacturing, medical informatics, digital libraries, mobile computing, and electronic commerce (ISF homepage). The aim of the journal and its multidisciplinary approach is reflected in the composition of $I S F$ Advisory Board members which include Noble Prize winners (e.g. Kenneth Arrow, Stanford University), National Academy of Engineering members (e.g. Arun Netravali, Past President of Bell Labs and Chief Scientist of Lucent) and Captains of industry (e.g. Ellen M. Knapp, PricewaterhouseCoopers; Satyen N. Mukherjee, Philips Research Laboratories; Narayana N.R. Murthy, Infosys Technologies Ltd.; and Suek Namgoong, Samsung Data Systems). The board also includes some of the renowned academics from various discipline including principal founder and intellectual architect of the academic field of information systems - Gordon Davis, University of Minnesota; and economist, computer scientist and winner of the LEO Award for Lifetime Exceptional Achievement in Information Systems Andrew B. Whinston, University of Texas at Austin (ISF homepage ${ }^{5}$ ).

2008 was an important milestone for ISF since its publication started off with its inaugural issue in 1999 (Ramesh and Rao 2008). On this occasion the ISF editors (see Ramesh and Rao 2008, p1-2) reflected on some of the journal's achievements over the past ten years, including the fact that "ISF has indeed provided a vibrant forum for both academicians and industry specialists to explore the multiple frontiers of the IS/IT field and has brought innovative research on all aspects of IS/IT from analytical, behavioral and technological perspectives" (Ramesh and Rao 2008, p1-2). One of the ways in which ISF achieved its aim to be frontiers of IS was by commissioning cutting-edge special issues that were guest edited by leading experts of the area from across the globe on a wide range of topics. Examples of such topics include - Information Dynamics, IT Investment Payoffs, Cyber Law, Knowledge Discovery in High Throughput Biological Domains, Philosophical Reasoning in Information Systems Research, and Secure Knowledge Management (Ramesh and Rao 2008). Some of the recently published (such as ICT in the Residential and Household Context) and the forthcoming guestedited issues on "Ambient Intelligence and Intelligent Systems and Smart Homes provides evidence of ISF's continuous efforts to foster creativity at the emerging disciplinary interfaces leading to new frontiers in IS/IT research" (Ramesh and Rao 2008, p1-2). Although editors have provided some indication of $I S F$ 's evolution and achievements, an in-depth analysis by

\footnotetext{
${ }^{2}$ http://www.acphis.org.au/index.php?option=content \&task=category \&sectionid=6\&id=33\&Itemid=53

3 http://www.the-abs.org.uk/?id=257

4 http://www.springer.com/business/business+information+systems/journal/10796?detailsPage=aimsAndScopes

5 http://www.springer.com/business/business+information+systems/journal/10796?detailsPage=editorialBoard
} 
profiling ten years of its publications would be of great interest to the $I S F$ readership as it will uncover the intellectual wealth which has evolved over a ten-year period.

With reference to journal publications, profiling is considered to be an art of introspection that aims to benefit a specific audience, and takes a journal towards the right and balanced direction (Dwivedi et al. 2008; Dwivedi and Kuljis 2008; Palvia et al. 2007). For the benefit of ISF's audience, this paper provides an overview of research published in the journal which is intended to help them to appreciate and identify topics worthy of research and publication (Palvia et al. 2007). Also, such efforts will provide a valuable addition towards the efforts exerted by Avison et al. (2008), Claver et al. (2000), Dwivedi et al. (2008), Dwivedi and Kuljis (2008) and Palvia et al. (2007) towards understanding and developing the area of IS research. Furthermore, our study is likely to stimulate researchers to profile other IS Journals in order to conduct comparative/cross-journal studies which will ultimately help to understand the overall evolution of the IS discipline.

Before stating the aim and objectives of the paper it is important to evaluate the $I S F$ literature focusing upon research agenda, evolution of IS field, and theoretical and methodological issues. Our literature search suggests that $I S F$ has published many such articles, most notably a paper on "Team Theory and Distributed Processing" (Arrow 1999) and a foreword on "Information Dynamics in the Networked World" (Arrow 2003) both by Noble Laureate Prof. Kenneth Arrow and a paper by one of the founders of IS - Prof. Gordon Davis - entitled "A Research Perspective for Information Systems and Example of Emerging Area of Research" (Davis 1999). Further to this, Freeman's (2001) work established IS Foundations, Definitions and Applications. Another notable contribution in this area is by Gray and Hovav (1999) on identifying frontiers of IS based on scenario. On the methodological and theoretical side, Adam and Richardson (2001) examined feminist philosophy and Dobson (2001) discussed philosophy of critical realism. A number of studies successfully attempted to explore and limit the boundary of emerging sub domains including electronic commerce (Shaw 1999), knowledge management (Sage and Rouse 1999), philosophy of information technology and systems as tools (Bunker 2001), workflow automation: overview and research issues (Stohr and Zhao 2001), philosophical underpinnings of software engineering research (Gregg et al. 2001) and semantic web services (Bell et al. 2007). A recently published guest editorial attempted to profile adoption and diffusion research from a household/consumer perspective (Dwivedi et al. 2008a). The publication of these studies clearly indicates that $I S F$ regularly publishes articles focusing on various facets of IS research evolution. This paper will be a further contribution towards understanding the evolution of the IS discipline from the ISF's perspective.

In light of the above, the aim of this paper is to provide a systematic review of ISF publications in order to ascertain their current "state of play" along a number of dimensions. This overall aim is realised by means of the following objectives: 1 . To identify the most prolific authors published in $I S F ; 2$. To determine the gender of contributing authors; 3 . To determine the occupation/position of contributing authors; 4. To identify authors' backgrounds (i.e. home departments and academic, or practitioner); 5. To perform co-author analysis; 6 . To identify the universities associated with the most research publications; 7 . To determine the geographic location of contributing authors; 8. To classify ISF publications according to the research methods employed; 9. To determine the most frequently used keywords in ISF publications; 10. To determine the research impact of the published research by undertaking citations analysis; and 11 . To examine the knowledge transfer from other academic outlets to the $I S F$.

In order to achieve these objectives, a systematic review of 307 articles published during the period 1999-2008 was conducted. The remainder of this paper is structured as follows. Section 2 provides a discussion of the method employed in the analysis of the published ISF research. The findings are presented and discussed in Section 3. Finally, Section 4 presents conclusions from this work and the limitations of the approach. 


\section{Research methodology}

In order to create a profile of the research methods, universities, and authors, the study thoroughly examined all ISF papers published between the years 1999 and 2008. The authors carefully reviewed a total of 307 research articles to capture data on these variables. Such an approach for the systematic classification of research published in a particular journal is termed as a 'meta-study' or 'longitudinal literature review' (Palvia et al. 2007; Dwivedi et al. 2008). Since this approach has been successfully employed previously to profile a number of IS and related journals, including the European Journal of Information Systems (EJIS) (Dwivedi and Kuljis 2008), Information \& Management (I\&M) (Claver et al. 2000; Palvia et al. 2007), the Information Systems Journal (ISJ) (Avison et al. 2008) and Journal of Electronic Commerce Research (JECR) (Dwivedi et al. 2008), we also utilised it to profile $I S F$ publications.

Various items were recorded for each article including the citations of selected articles, geographic regions, authors' backgrounds and the research methods used by the authors. The impact of the research was assessed using both Web of Science (WoS) and Google Scholar citation counts. Institutional contributions/productivity were examined by utilising an adjusted count approach in which only one count was allocated to authors from the same institution (Palvia et al. 2007; Dwivedi et al. 2008; Dwivedi and Kuljis 2008). Both the authors' backgrounds and geographic location variables were adapted from previous studies (Avison et al. 2008; Dwivedi et al. 2008). However, following the arguments put forward by Dwivedi et al. (2008), we further divided the three regions suggested by the Association of Information Systems (AIS) into seven regions to reflect the true picture of the publication activity from different geographic regions. AIS divided the world into the following three regions: (1) AIS Region 1 - Americas; (2) AIS Region 2 - Europe, Africa and Middle East; and (3) AIS Region 3 - Asia Pacific. For the purpose of this study we modified this scheme and divided the regions into the following seven categories: (1) AIS-R1- USA \& Canada; (2) AIS-R1- Other (Latin American \& South American Countries); (3) AIS-R2- Europe \& UK; (4) AIS-R2- Middle East \& Africa; (5) AIS-R3- South Korea, Singapore, Hong Kong, Taiwan, China, Japan, India; (6) AIS-R3- Australia \& New Zealand; and (7) AIS-R3- Other.

The categories for recording the research methods' related aspects were adapted from previous studies (Avison et al. 2008; Dwivedi et al. 2008; Palvia et al. 2007). A number of research method categories (e.g. Descriptive/Theoretical/Conceptual, Survey, Experiment, Case Study, Data Analysis, Interview, and Ethnographic Studies) were employed to classify $I S F$ publications. Although, due to space limitations, it is not appropriate to provide detailed information on these categories, readers can refer to the original sources (Avison et al. 2008; Palvia et al. 2007; Dwivedi et al. 2008) for more detail.

It is important to emphasise at this point that like previous profiling studies (Claver et al. 2000; Palvia et al. 2007) the findings of this study, in terms of universities with the most contributors, should be regarded as 'indicative and not an authoritative declaration' (Palvia et al. 2007). This is because it is possible that some universities may have niches of research expertise that are not yet visible.

\subsection{Knowledge transfer from other journals to ISF}

In this section, the methodology associated with performing co-citation analysis of citation data pertaining to $I S F$ journal is described. The citation data is obtained from the ISI Web of Knowledge database and it contains a total of 241 articles and reviews. The issues that make up this data set start from 3(3):377-392 and end at 10(4):483-497, encompassing a period from September 2001 to September 2008 respectively. The co-citation analysis is performed using the Knowledge Domain Visualization (KDViz) software called CiteSpace (Chen, 2004). The research method for this purpose is described below. 
Step 1: Citation data pertaining to ISF journal is downloaded from the ISI Web of Knowledge database in ISI format.

Step 2: The citation data is fed into CiteSpace. This is achieved through creating a new project and mapping the directory containing the citation data from within the CiteSpace program.

Step 3: Various CiteSpace options are selected. These include (a) the time interval of analysis (2001-2008); (b) the unit of analysis (1 year); (c) the citation threshold (between 2 and 3); (d) the co-citation threshold (between 2 and 3); (e) the pruning and merging option (pathfinder network scaling); and (f) the visualisation option (merged network cluster view). The reader is referred to Chen (2006) for an extensive discussion of these variables.

Step 4: Nodes and links are the building blocks of a co-citation network. CiteSpace supports a total of eight different Node Types (NT). Each NT is associated with a particular type of analysis. For this paper we have performed a total of four different analyses using the following four different NTs:

(a) Articles that can be considered as intellectually significant (NT references)

(b) Articles with high citations (NT references)

(c) Journals that are highly cited by ISF authors (NT cited authors)

(d) Mapping the evolution of IS (NT noun phrases)

Step 5: The result of the analysis has been described below in the findings section. A combination of tables and figures has been used to report the findings.

\section{Findings and discussion}

The findings of this study are presented in the following subsections. The first subsection presents the most productive authors and then the variables related with the authors such as gender, occupation, departments, and academic or industry association. This follows the coauthor analysis to show the collaborative nature of the research published in $I S F$. Following this, geographical diversity and the authors' university and country information is presented.

Next, we profile the publication by the research method utilised. The next two subsections discuss the most frequently utilised keywords and noun phrases published in ISF. This is followed by citation analysis to illustrate the research impact of the most inferential studies. The last three subsections present analysis on the influence of other publishing outlets on IS researchers in terms of intellectually significant articles, articles highly cited by $I S F$ authors, and journals highly cited within $I S F$ publications.

\subsection{Most productive authors}

An analysis is conducted to identify those authors who published the most in the 10-year period (1999-2008) in $I S F$. Similar to the study by Palvia et al. (2007), for assessing research productivity the normal count approach is employed. Palvia et al. (2007) suggested that all publications naming the researcher should be counted equally (i.e. an article with three coauthors would provide one count for each). However, this approach results in the combined count of all authors being greater than the total number of articles (Palvia et al. 2007). 
For presenting the findings of this study, only those authors who have published three or more articles during the period studied are included in the list. A total of 694 authors contributed to the 307 articles of $I S F$. Table 1 lists the 9 most productive authors, ordered according to the number of articles published in $I S F$ during the study period, and also each author's most recent affiliation. The findings suggest that only two authors (Amjad Umar and Michael J. Shaw) have contributed to four publications each. The remaining seven authors in Table 1 each contributed to three articles. Although not listed in the Table, 42 authors contributed to two articles each and finally, the largest number of authors $(C=642)$ contributed to one article each.

Table 1 The most productive authors who published three or more papers in ISF between 1999 and 2008 (approach adapted from Dwivedi and Kuljis 2008; Palvia et al. 2007).

\begin{tabular}{llccl}
\hline SL & $\begin{array}{l}\text { Author Name } \\
(\mathrm{n}=694)\end{array}$ & $\begin{array}{c}\text { Count } \\
(\mathrm{N}=307)\end{array}$ & Gender & Most Recent Affiliation \\
\hline 1 & Amjad Umar & 4 & $\mathrm{M}$ & Fordham University \\
2 & Michael J. Shaw & 4 & $\mathrm{M}$ & University of Illinois at Urbana-Champaign \\
3 & Ramesh Sharda & 3 & $\mathrm{M}$ & Oklahoma State University \\
4 & Kweku-Muata Osei-Bryson & 3 & $\mathrm{M}$ & Virginia Commonwealth University \\
5 & Andrew B. Whinston & 3 & $\mathrm{M}$ & University of Texas at Austin \\
6 & Ozgur Turetken & 3 & $\mathrm{M}$ & Ryerson University \\
7 & Lida Xu & 3 & $\mathrm{M}$ & Old Dominion University \\
8 & Rudy Hirschheim & 3 & $\mathrm{M}$ & Louisiana State University \\
9 & Susan A. Sherer & 3 & F & Lehigh University \\
\hline
\end{tabular}

In terms of the most productive authors, although the lists provided in the $I \& M$ study (Palvia et al. 2007) and in this study both include renowned authors, none of the authors appeared in both the studies. This simply indicates that each journal has their specific author population for generating intellectual wealth by contributing the scholarly articles. Author population for each journal is large but the population of loyal authors who prefer to contribute to specific journals a number of times are very few. We believe that such authors understand the editorial policy, quality criteria and review process of their preferred journal well enough that they manage to publish more than two or three articles in the same journals. The findings of Palvia et al. (2007) and this research clearly suggest that future researchers reporting findings on the most productive authors based on only one publishing outlet should be cautious when making authoritative claims.

\subsection{Gender of authors}

Gender information of a total of 726 (95.8\%) authors was extracted from authors' biographies; however, it was not possible to determine the gender of 32 (4.2\%) authors due to a lack of such information in their biographies or due to complete lack of biography in certain articles. The analysis presented in Table 2 suggests that the proportion of male authors is much higher than females. A total of $589(77.7 \%)$ male authors contributed articles in $I S F$. A much lower proportion of female authors $(\mathrm{C}=137,18.1 \%)$ made intellectual contributions to the journal.

Table 2 Gender of ISF authors (approach adapted from Avison et al. 2008)

\begin{tabular}{lcc}
\hline & Frequency & Percent \\
\hline Male & 589 & 77.7 \\
Female & 137 & 18.1 \\
Total & 726 & 95.8 \\
Unknown & 32 & 4.2 \\
Total & 758 & 100.0 \\
\hline
\end{tabular}




\subsection{Occupation of authors}

The data presented in Table 3 suggests that the highest proportion of ISF authors hold professorship positions. This is then followed by associate professor and assistant professor positions. An almost equal number of authors were either doctoral candidates $(\mathrm{C}=75,9.89 \%)$ or researchers $(\mathrm{C}=74,9.76 \%)$, followed by authors from industry (i.e. practitioners) whose role it was not possible to specify, and then lecturers and senior lecturers and a variety of other occupations, not all of which are listed below. Other less frequently reported roles/positions not listed in Table 3 include Assistant Registrar, Lab Manager, Systems Analyst, Senior Technologist, Project Director, Software Engineer, General Manager, IT Architect, Senior Clinical Investigator, Business architect, Biostatistician, Chief Knowledge Officer, Research Coordinator, Systems Architect, Program Manager, Web Developer, Strategy Analyst, Assistant Manager, Senior Software Developer, Software Factory Manager, Assistant Professor, Group Leader, Quality Manager and Attorney.

Table 3 Occupation of authors

\begin{tabular}{lcc}
\hline Occupation & Frequency & Percent \\
\hline Professor & 201 & 26.52 \\
Associate Professor & 95 & 12.53 \\
Assistant Professor & 88 & 11.61 \\
Researcher & 75 & 9.89 \\
Ph.D. candidate & 74 & 9.76 \\
Practitioner & 35 & 4.62 \\
Lecturer & 29 & 3.83 \\
Senior Lecturer & 22 & 2.90 \\
Research Scientist & 7 & 0.92 \\
Senior Research Scientist & 5 & 0.66 \\
Consultant & 5 & 0.66 \\
Scientist & 5 & 0.66 \\
Engineer & 4 & 0.53 \\
Principal Research Scientist & 3 & 0.40 \\
Chief Executive Officer & 2 & 0.26 \\
Research Leader & 2 & 0.26 \\
Software Architect & 2 & 0.26 \\
Project Manager & 2 & 0.26 \\
Reader & 2 & 0.26 \\
Physician & 2 & 0.26 \\
\hline
\end{tabular}

\subsection{Area of academic expertise/authors home department}

In terms of the number of authors/contributors from different departments, the largest number of contributors were located in the Information Systems (IS) department (198, 26.1\%), which is followed by Computer Science/Software Engineering $(160,21.1 \%)$, Business Administration (67, 8.8\%), Management (61, 8\%), IT/IT Management (53, 7\%), Engineering (45, 5.9\%), Information Science/Library Science (31, 4.1\%), Industrial Administration/Industrial Production (22, 2.9\%), Accounting and Information Management/Operations Management, both categories with 18 authors each, Decision Sciences and Economics, both with 16 authors each, Social Sciences/Studies Philosophy/Sociology (15, 1.6\%), Maths/Statistics (14, 1.8\%), and Bio Informatics/Health Informatics/Medical Informatics (12, 1.6\%). All other departments associated with relatively few authors, including Electronic Commerce/E-Business which associated with only 10 (1.3\%) authors (see Table 4).

Table 4 Authors' academic background (i.e. home department) (approach and categories adapted from Avison et al. 2008; Dwivedi et al. 2008)

\begin{tabular}{|l|l|l|}
\hline Discipline & Count & Percent \\
\hline
\end{tabular}




\begin{tabular}{|l|c|c|} 
Accounting & 18 & 2.4 \\
\hline Business Administration & 67 & 8.8 \\
\hline Bio Informatics/Health Informatics/Medical Informatics & 12 & 1.6 \\
\hline Computer Science/Software Engineering & 160 & 21.1 \\
\hline Decision Sciences & 16 & 2.1 \\
\hline Economics & 16 & 2.1 \\
\hline E-Commerce & 10 & 1.3 \\
\hline Engineering & 45 & 5.9 \\
\hline Finance & 3 & 0.4 \\
\hline Information Science/Library Science & 31 & 4.1 \\
\hline Information Systems/MIS & 198 & 26.1 \\
\hline Information Management/Operations Management & 18 & 2.4 \\
\hline IT/ICT Management & 53 & 7.0 \\
\hline Industrial Administration/Industrial Production & 22 & 2.9 \\
\hline Law & 5 & 0.7 \\
\hline Management/MS/OR & 61 & 8.0 \\
\hline Maths/Statistics & 14 & 1.8 \\
\hline Marketing & 6 & 0.8 \\
\hline Communications & 11 & 1.5 \\
\hline Psychology/Behavioural Research & 3 & 0.4 \\
\hline Social Sciences/Studies - Philosophy/Sociology & 15 & 2.0 \\
\hline Others /Industry & 137 & 18.1 \\
\hline
\end{tabular}

\subsection{Background of authors}

Table 5 illustrates the number of authors/contributors from academia or industry. The largest number of contributors were from academia $(651,85.88 \%)$ and a comparatively small proportion of authors were based in industry $(107,14.12 \%)$ (Table 5).

Table 5 Authors' background (approach and categories adapted from Avison et al. 2008; Dwivedi et al. 2008)

\begin{tabular}{lcc}
\hline Authors' Background & Count & Percent \\
\hline Academic & 651 & 85.88 \\
Industry/Others & 107 & 14.12 \\
Total & 758 & 100 \\
\hline
\end{tabular}

\subsection{Co-author analysis}

In terms of the number of co-authors who contributed to each article, $10.03 \%(\mathrm{C}=76)$ of the articles were written by one author (Single Authored). Articles produced by multiple authors form the following categories: $12.27 \%(\mathrm{C}=93)$ articles were co-authored by two authors, forming the largest category, $11.87 \%(\mathrm{C}=90)$ articles by three authors, $3.83 \%(\mathrm{C}=29)$ articles by four authors, $1.45 \%(\mathrm{C}=11)$ articles by five authors, five articles were co-authored by six authors and then two articles have seven authors each. Only one article was co-authored by ten authors (see Table 6).

Table 6 Pattern of co-authorship of $I S F$ articles (approach adapted from Avison et al. 2008; Dwivedi et al. 2008)

\begin{tabular}{ccc}
\hline Number of Co-authors & Count & Percent \\
\hline 1 & 76 & 10.03 \\
2 & 93 & 12.27 \\
3 & 90 & 11.87 \\
4 & 29 & 3.83 \\
5 & 11 & 1.45 \\
6 & 5 & 0.66 \\
\hline
\end{tabular}




\begin{tabular}{ccc}
\hline 7 & 2 & 0.26 \\
10 & 1 & 0.13 \\
Total & 307 & 40.50 \\
\hline
\end{tabular}

\subsection{Leading research universities}

Authors/contributors from 345 organisations/universities contributed to one or more articles in $I S F$ between 1999 and 2008. Table 7 presents the top 17 universities having four or more articles published in the journal. The following is a breakdown of the frequency of contributors/authors affiliated with a particular organisation or university. Two universities ranked first, contributing seven articles each. This is followed by two universities who each contributed six articles and four universities who each contributed five articles each. The remaining eight from 17 universities listed in Table 7 contributed four articles each. 25 organisations contributed three articles each, followed by 43 organisations who contributed two articles each. Finally, the largest number $(\mathrm{C}=260)$ of universities had affiliations with one contribution from each.

Table 7 Top 17 universities (with four or more publications) published in ISF (1999-2008) (approach adapted from Avison et al. 2008; Dwivedi et al. 2008; Palvia et al. 2007)

\begin{tabular}{llcc}
\hline & Universities & Country & Count \\
\hline 1 & Arizona State University & USA & 7 \\
2 & Claremont Graduate University & USA & 7 \\
3 & Carnegie Mellon University & USA & 6 \\
4 & University of Arizona & USA & 6 \\
5 & Brunel University & UK & 5 \\
6 & IBM & Various & 5 \\
7 & University of Illinois at Urbana-Champaign & USA & 5 \\
8 & Old Dominion University & USA & 5 \\
9 & University of Twente & The Netherlands & 5 \\
10 & Telcordia Technologies Inc., & USA & 4 \\
11 & University of Texas at Austin & USA & 4 \\
12 & University of Waterloo & Canada & 4 \\
13 & Louisiana State University & USA & 4 \\
14 & George Mason University & USA & 4 \\
15 & City University of Hong Kong & Hong Kong & 4 \\
16 & State University of New York at Buffalo & USA & 4 \\
17 & Penn State University & USA & 4 \\
\hline
\end{tabular}

An observation similar to the most productive authors has been made in terms of most productive institutions. Only a few institutions appear in more than one study including the list of institutions obtained in our research. Such examples include Arizona State University, University of Arizona, City University of Hong Kong and George Mason University (Dwivedi et al. 2008; Palvia et al. 2007). This supports the argument provided in the methodology section that the findings of such studies in terms of institutional productivity should be regarded as 'indicative and not an authoritative declaration' (Dwivedi et al. 2008; Palvia et al. 2007). However, one significant difference that can be noted from the analysis of $I S F$ publications is the large number of commercial organisations, many of whom are leaders in IT industry, such as IBM and HP.

\subsection{Country and geographical regions}

A total of 33 countries' authors published in ISF between the years 1999 and 2008 (Table 8). In terms of the number of authors/contributors from different countries, the largest number of contributors were located in the USA $(369,48.68 \%)$, followed by the UK $(51,6.73 \%)$. The third largest category $(44,5.80 \%)$ was formed by German authors and Canadians $(42,5.54 \%)$ are in fourth place. Table 8 illustrates the proportion of contributors from the 33 countries. 
Table 8 Contributors' geographical location (approach adapted from Avison et al. 2008; Dwivedi et al. 2008)

\begin{tabular}{clccclcc}
\hline SL & \multicolumn{1}{c}{ Country } & Count & Percent & SL & Country & Count & Percent \\
\hline 1 & USA & 369 & 48.68 & 18 & Denmark & 5 & 0.66 \\
2 & UK & 51 & 6.73 & 19 & Norway & 5 & 0.66 \\
3 & Germany & 44 & 5.80 & 20 & India & 3 & 0.40 \\
4 & Canada & 42 & 5.54 & 21 & Argentina & 3 & 0.40 \\
5 & China & 34 & 4.49 & 22 & Turkey & 3 & 0.40 \\
6 & Australia & 31 & 4.09 & 23 & Singapore & 3 & 0.40 \\
7 & The Netherlands & 25 & 3.30 & 24 & Jamaica & 2 & 0.26 \\
8 & South Korea & 22 & 2.90 & 25 & Iran & 2 & 0.26 \\
9 & Hong Kong & 21 & 2.77 & 26 & New Zealand & 2 & 0.26 \\
10 & Italy & 20 & 2.64 & 27 & Austria & 2 & 0.26 \\
11 & Sweden & 13 & 1.72 & 28 & Spain & 2 & 0.26 \\
11 & Taiwan & 12 & 1.58 & 29 & Brazil & 2 & 0.26 \\
13 & Japan & 10 & 1.32 & 30 & Switzerland & 2 & 0.26 \\
14 & Greece & 8 & 1.06 & 31 & Slovenia & 1 & 0.13 \\
15 & Israel & 6 & 0.79 & 32 & Ireland & 1 & 0.13 \\
16 & Belgium & 6 & 0.79 & 33 & Oman & 1 & 0.13 \\
17 & Finland & 5 & 0.66 & & Total & 758 & 100 \\
\hline
\end{tabular}

In terms of the number of authors from different geographical regions (as per the Association of Information Systems (AIS)), the largest number of authors were from the AIS Region 1 USA and Canada (411, 54.22\%), followed by the AIS Region 2 - Europe and UK with $25.07 \%(\mathrm{C}=190)$ of the authors. The third largest category was formed by the AIS Region 3 South Korea, Singapore, Hong Kong, Taiwan, China, Japan, India with $13.72 \%(C=104)$ of the authors (Table 9) followed by AIS-R3- Australia \& New Zealand with $4.49 \%(C=34)$ of the authors. The other three less active regions are also illustrated in Table 9.

Table 9 Geographical regions of $I S F$ authors (approach adapted from Dwivedi et al. 2008)

\begin{tabular}{lcc}
\hline Geographical Region (AIS Classification) & Count & Percent \\
\hline AIS-R1- USA \& Canada & 411 & 54.22 \\
AIS-R2- Europe \& UK & 190 & 25.07 \\
AIS-R3- South Korea, Singapore, Hong Kong, Taiwan, China, Japan, India & 104 & 13.72 \\
AIS-R3- Australia \& New Zealand & 34 & 4.49 \\
AIS-R2- Middle East \& Africa & 12 & 1.58 \\
AIS-R1-Other (Latin American \& South American Countries) & 7 & 0.92 \\
AIS-R3- Other & 0 & 0 \\
Total & 758 & 100 \\
\hline
\end{tabular}

Avison et al.'s (2008) research on the review of ISJ and Dwivedi et al.'s (2008) review of JECR show that a number of geographical regions (such as South America, the Middle East, the Former Soviet Union and many underdeveloped countries of Asia) are under-represented in terms of undertaking and publishing information systems and electronic commerce research (Avison et al. 2008; Dwivedi et al. 2008). Our investigation also reveals highly under-represented levels of information systems from the Southern and Central American Regions and no representation from AIS-R3 - other countries, such as Afghanistan, Bangladesh, Cambodia, Indonesia, Malaysia, Nepal, Pakistan, Sri Lanka, and Thailand (see Tables 8-9). Like previous works (Avison et al. 2008; Dwivedi et al. 2008), this highly imbalanced picture certainly raises an important research agenda for IS researchers to investigate: whether this situation is a consequence of a global IS digital divide or whether it is due to a lack of interest or lack of necessary expertise to undertake IS research within such countries (Dwivedi et al. 2008). In either case, the problem of a potential global IS divide needs to be investigated and academics from IS hotspots such as the USA, UK, Australia, Hong Kong, Taiwan, Korea, and European countries should consider collaboration with 
researchers from under-represented regions in order to undertake more fruitful research which is critical to the global emergence of information systems (Dwivedi et al. 2008).

Furthermore, this study also endorses arguments of a previous work (Dwivedi et al. 2008) on the appropriateness of using the AIS Regions for geographical comparison. Dwivedi et al. (2008) argued that researchers should divide the AIS Region 2 into three sub-divisions, namely European regions, the Middle East and Africa. Similarly, the AIS Region 1 should be divided into North and South America, and the AIS Region 3 should be divided into the Pacific Region (Australia and New Zealand), active Asian nations such as Singapore, Hong Kong, South Korea, Japan, Taiwan, China, and India, and comparatively less active Asian regions such as Afghanistan, Bangladesh, Cambodia, Indonesia, Malaysia, Nepal, Pakistan, Sri Lanka, Thailand, and many other countries. Without such finer divisions it will not be possible to develop a clear picture of the regional growth of information systems and electronic commerce practice and research (Dwivedi et al. 2008). Profiling of ISF provides empirical evidence for such a view and therefore we recommend that researchers follow the modified classification scheme described above for the purpose of future research.

\subsection{Research methods}

The findings suggest that although a total of eight different research methods were recorded from our data analysis activities, the majority of studies within our results employed analytical/conceptual/descriptive/theoretical methods $(223,72.6 \%$ ) (this includes various related methods such as view points, commentary, review, meta-analysis, design, simulation, algorithm, and mathematical modelling), case study $(22,7.2 \%)$, experiment $(21,6.8 \%)$ and survey $(18,5.9 \%)$ methods. The other categories employed were the secondary data analysis $(7,2.3 \%)$, multi-method $(3,1 \%)$, interview $(3,1 \%)$, event study $(3,1 \%)$, observation $(2$, $0.7 \%)$, content analysis $(2,0.7 \%)$, case based reasoning $(2,0.7 \%)$, action research $(1,0.3 \%)$ and ethnographic method $(1,0.3 \%)$ (see Table 10). Previous such studies have argued and illustrated that more papers published in the early stages of emergence are likely to be descriptive/conceptual/theoretical in nature (Avison et al. 2008, Dwivedi et al. 2008, Wareham et al. 2005). Avison et al. (2008), Dwivedi et al. (2008) and Wareham et al. (2005) revealed a large number of descriptive/conceptual/theoretical papers in the early years of publication, which is clearly evident from this investigation too (see Table 10).

Table 10 Research methods employed (categories adapted from Avison et al. 2008, Chen and Hirschheim 2004, Dwivedi et al. 2008)

\begin{tabular}{lrr}
\hline Research Methods & Count & Percent \\
\hline Analytical/Conceptual/Descriptive/ Theoretical* & 223 & 72.6 \\
Case Study & 22 & 7.2 \\
Experiment & 21 & 6.8 \\
Survey & 18 & 5.9 \\
Secondary Data Analysis & 7 & 2.3 \\
Multi-Method & 3 & 1.0 \\
Interview & 3 & 1.0 \\
Event Study & 3 & 1.0 \\
Content Analysis & 2 & .7 \\
Case Based Reasoning & 2 & .7 \\
Observation & 2 & .7 \\
Action Research & 1 & .3 \\
Ethnographic Studies & 1 & .3 \\
*This category includes various methods such as View Points, Commentary, Review, \\
Meta-analysis, Design, Simulation, Algorithm, Mathematical Modelling \\
\hline
\end{tabular}




\subsection{Keyword analysis: popular keywords}

In order to assess the most frequently utilised (employed) keywords, all the keywords were collected. These keywords were then sorted into alphabetical order to explore the most frequently utilised keywords. A total of 23 keywords were used five or more times. These 23 keywords, along with their frequency, are listed in Table 11. 'Systems' and 'model' were the most frequently used keywords, with 18 papers utilising them, followed by 'technology' and 'performance', each represented by 13 articles. 'Management' emerged as the fifth most utilised keyword as 12 studies used this keyword. This was closely followed by 'web services' (9), 'design' (9), 'information' (8), and 'knowledge management' (7). Table 11 summarises the frequency of usage of the 23 most frequently utilised keywords. The trend of keyword utilisation suggests that $I S F$ are frontiers of novel research in the area of IS design, applications, and management. We also identified a few keywords that have influenced the thinking and publication practices of $I S F$ 's audience. These keywords include 'performance', 'model', 'knowledge', 'knowledge management', and 'outsourcing' (Table 11).

Table 11 Most frequently utilised keywords

\begin{tabular}{lclc}
\hline Keywords & Freq & Keywords & Freq \\
\hline systems & 18 & information technology & 5 \\
model & 18 & issues & 5 \\
technology & 13 & scale & 5 \\
performance & 13 & trust & 5 \\
management & 12 & Information systems & 5 \\
web services & 9 & methodology & 5 \\
design & 9 & Turning point keywords (identified by CiteSpace) \\
information & 8 & performance & 13 \\
knowledge management & 7 & systems & 18 \\
security & 6 & model & 18 \\
information-technology & 6 & technology & 13 \\
outsourcing & 6 & management & 12 \\
supply chain management & 6 & information & 8 \\
architecture & 5 & methodology & 5 \\
information systems & 5 & knowledge & 5 \\
knowledge & 5 & outsourcing & 6 \\
integration & 5 & knowledge management & 7 \\
\hline
\end{tabular}

\subsection{Mapping the evolution of IS based on ISF publications}

The Node Type noun phrase has been used for this analysis (see the methodology section for more details). CiteSpace defines a noun phrase as a number of consecutive nouns, which may or may not have been modified by one or more adjectives (CiteSpace Wiki 2008). CiteSpace extracts noun phrases from paper titles and abstracts that have been downloaded from the ISI Web of Knowledge database. It is important to note that noun phrases are not the same as user-defined keywords, although some of the noun phrases may be used as keywords by the authors. Noun phrase analysis provides insights into the evolution of IS over the years (Table 12).

Table 12 Evolution of IS through noun phrase analysis

\begin{tabular}{|c|c|c|c|c|}
\hline year & noun phrase & noun phrase & noun phrase & noun phrase \\
\hline \multirow[t]{5}{*}{2001} & information systems & supply chain & inquiring systems & $\begin{array}{l}\text { information systems } \\
\text { development }\end{array}$ \\
\hline & systems & methodology & science & $\begin{array}{l}\text { group support } \\
\text { systems }\end{array}$ \\
\hline & technology & $\begin{array}{l}\text { organisational } \\
\text { learning }\end{array}$ & business processes & $\begin{array}{l}\text { supply chain } \\
\text { operations }\end{array}$ \\
\hline & management & new approach & $\begin{array}{l}\text { workflow } \\
\text { management system }\end{array}$ & $\begin{array}{l}\text { decision support } \\
\text { systems }\end{array}$ \\
\hline & design & knowledge & petri nets & systems development \\
\hline
\end{tabular}




\begin{tabular}{|c|c|c|c|c|}
\hline & $\begin{array}{l}\text { knowledge } \\
\text { management } \\
\text { information } \\
\text { supply chain } \\
\text { management }\end{array}$ & $\begin{array}{l}\text { various types } \\
\text { ethics } \\
\text { New York }\end{array}$ & $\begin{array}{l}\text { epistemology } \\
\text { software engineering } \\
\text { information system }\end{array}$ & $\begin{array}{l}\text { collaborative work } \\
\text { systems approach } \\
\text { philosophy of science }\end{array}$ \\
\hline 2002 & $\begin{array}{l}\text { information } \\
\text { technology } \\
\text { business process } \\
\text { architecture } \\
\text { electronic markets }\end{array}$ & $\begin{array}{l}\text { electronic } \\
\text { marketplaces } \\
\text { simulation } \\
\text { data mining } \\
\text { virtual organizations }\end{array}$ & $\begin{array}{l}\text { discrete-event } \\
\text { simulation } \\
\text { resource } \\
\text { management } \\
\text { object-oriented } \\
\text { analysis } \\
\text { sample data }\end{array}$ & $\begin{array}{l}\text { standard methods } \\
\text { wide variety }\end{array}$ \\
\hline 2003 & $\begin{array}{l}\text { performance } \\
\text { electronic commerce }\end{array}$ & $\begin{array}{l}\text { web } \\
\text { information } \\
\text { aggregation }\end{array}$ & $\begin{array}{l}\text { aggregation } \\
\text { productivity }\end{array}$ & $\begin{array}{l}\text { aggregate } \\
\text { information } \\
\text { mechanism design }\end{array}$ \\
\hline & $\begin{array}{l}\text { experimental } \\
\text { economics }\end{array}$ & security markets & rational expectations & risk \\
\hline 2004 & $\begin{array}{l}\text { model } \\
\text { e-commerce } \\
\text { service providers } \\
\text { service quality }\end{array}$ & $\begin{array}{l}\text { scale } \\
\text { customer satisfaction } \\
\text { mobile services } \\
\text { behavioural } \\
\text { intentions }\end{array}$ & $\begin{array}{l}\text { consumer } \\
\text { perceptions } \\
\text { price } \\
\text { middleware } \\
\text { key drivers }\end{array}$ & distributed systems \\
\hline 2005 & collaborative learning & & & \\
\hline 2006 & & & & \\
\hline 2007 & $\begin{array}{l}\text { web services } \\
\text { security }\end{array}$ & $\begin{array}{l}\text { integration } \\
\text { collaboration }\end{array}$ & $\begin{array}{l}\text { web service } \\
\text { service-oriented } \\
\text { computing }\end{array}$ & $\begin{array}{l}\text { heterogeneous } \\
\text { environments } \\
\text { model-driven } \\
\text { development }\end{array}$ \\
\hline 2008 & $\begin{array}{l}\text { IT outsourcing } \\
\text { outsourcing success }\end{array}$ & $\begin{array}{l}\text { issues } \\
\text { information systems }\end{array}$ & $\begin{array}{l}\text { trust } \\
\text { outsourcing }\end{array}$ & $\begin{array}{l}\text { information } \\
\text { technology }\end{array}$ \\
\hline
\end{tabular}

\subsection{Citation analysis}

A citation analysis was conducted to determine the research impact of the most influential authors and studies based on the number of ISF publication citations. Citation data (citation count and article frequency) from Google Scholar which was retrieved on May 1, 2008 and updated on September 12, 2008 for all 307 articles appearing in ISF between the years 1999 and 2008. Data obtained from Google Scholar on total citation count per article suggests that 20 articles were cited more than 50 times on average, and the 35 articles received citations above 20. Nine studies with larger values of citation counts from each year are listed in Table 13 which includes study with largest count by Ross and Vitale (2000) with a 180 citation count (as per Google Scholar). As noted by Dwivedi et al. (2008) regarding the citation count, older articles are more likely to have larger numbers of citations, while newer articles are likely to possess lower citation counts. This can be shown by the fact that articles possessing the largest number of citations were published in early volumes of ISF and none of the articles from a relatively recent volume had a larger count. This is not an unusual case as similar observations were recorded for the Journal of Electronic Commerce Research (Dwivedi et al. 2008).

Table 14 Most cited ISF articles (retrieved May 1, 2008, updated on September 12, 2008) (approach adapted from Dwivedi et al. 2008)

\begin{tabular}{lll}
\hline Study & $\begin{array}{l}\text { GS- } \\
\text { Citation }\end{array}$ & Article Title \\
\hline $\begin{array}{l}\text { Shaw M.J. (1999), Vol. 1, No. 1, pp. 95- } \\
\text { 106 }\end{array}$ & & $\begin{array}{l}\text { Electronic Commerce: Review of Critical } \\
\text { Research Issues }\end{array}$ \\
Ross J.W. \& Vitale M.R. (2000), Vol. 2, & 180 & The ERP Revolution: Surviving vs. Thriving \\
\hline
\end{tabular}




\begin{tabular}{|c|c|c|}
\hline No. 2, pp. 233-241 & & \\
\hline $\begin{array}{l}\text { Stohr E.A. \& Zhao J.L. (2001), Vol. 3, } \\
\text { No. 3, pp. 281-296 }\end{array}$ & 88 & $\begin{array}{l}\text { Workflow Automation: Overview and } \\
\text { Research Issues }\end{array}$ \\
\hline $\begin{array}{l}\text { Casati F. \& Shan M.-C. (2002), Vol. 4, } \\
\text { No. 1, pp. 19-31 }\end{array}$ & 20 & $\begin{array}{l}\text { Event-Based Interaction Management for } \\
\text { Composite E-Services in eFlow }\end{array}$ \\
\hline $\begin{array}{l}\text { Berg J.E. \& Rietz T.A. (2003), Vol. 5, } \\
\text { No. } 1 \text {, pp. } 79-93\end{array}$ & 63 & $\begin{array}{l}\text { Prediction Markets as Decision Support } \\
\text { Systems }\end{array}$ \\
\hline $\begin{array}{l}\text { Wang Y., Lo H.-P. \& Yang Y. (2004), } \\
\text { Vol. 6, No. 4, pp. } 325-340\end{array}$ & 22 & $\begin{array}{l}\text { An Integrated Framework for Service Quality, } \\
\text { Customer Value, Satisfaction }\end{array}$ \\
\hline $\begin{array}{l}\text { Ziegler C-N \& Lausen G. (2005), Vol. } \\
\text { 7, No. 4, pp. } 337-358\end{array}$ & 20 & $\begin{array}{l}\text { Propagation Models for Trust and Distrust in } \\
\text { Social Networks }\end{array}$ \\
\hline $\begin{array}{l}\text { Baker C.J.O. \& Witte R. (2006), Vol. } 8 \text {, } \\
\text { No. 1, pp. } 47-57\end{array}$ & 7 & Mutation Mining - A Prospector's Tale \\
\hline $\begin{array}{l}\text { Umapathy K. \& Purao S. (2007), Vol. 9, } \\
\text { No. 1, pp. 119-134 }\end{array}$ & 6 & $\begin{array}{l}\text { A Theoretical Investigation of the Emerging } \\
\text { Standards for Web Services }\end{array}$ \\
\hline
\end{tabular}

\subsection{Intellectually significant articles}

CiteSpace identifies potentially important articles in a co-citation network by enhancing the visual features of the nodes representing those articles (Chen 2004). Figure 1 shows a screenshot of articles (purple coloured nodes) that may be considered as intellectually significant for building the ISF's knowledge wealth. The information obtained in the figure is transposed to Table 14 . The table lists a total of 10 articles that are considered intellectually significant. Some of the rows in the table have a grey background. This shows the papers that also have a high level of citations (see next section). The identification of intellectually significant papers is only possible because CiteSpace does a time-sliced co-citation analysis, as opposed to a simplistic citation analysis. In this scheme of things, an article that has been co-cited many times within one time slice (say 1999-2000) may be considered less important than a paper that has been co-cited a fewer number of times but across different time slices (say 1999-2000, 2001-2003 and 2004-2006). This is only one example of how CiteSpace is able to detect potential intellectually significant articles, although its citation count may be less.

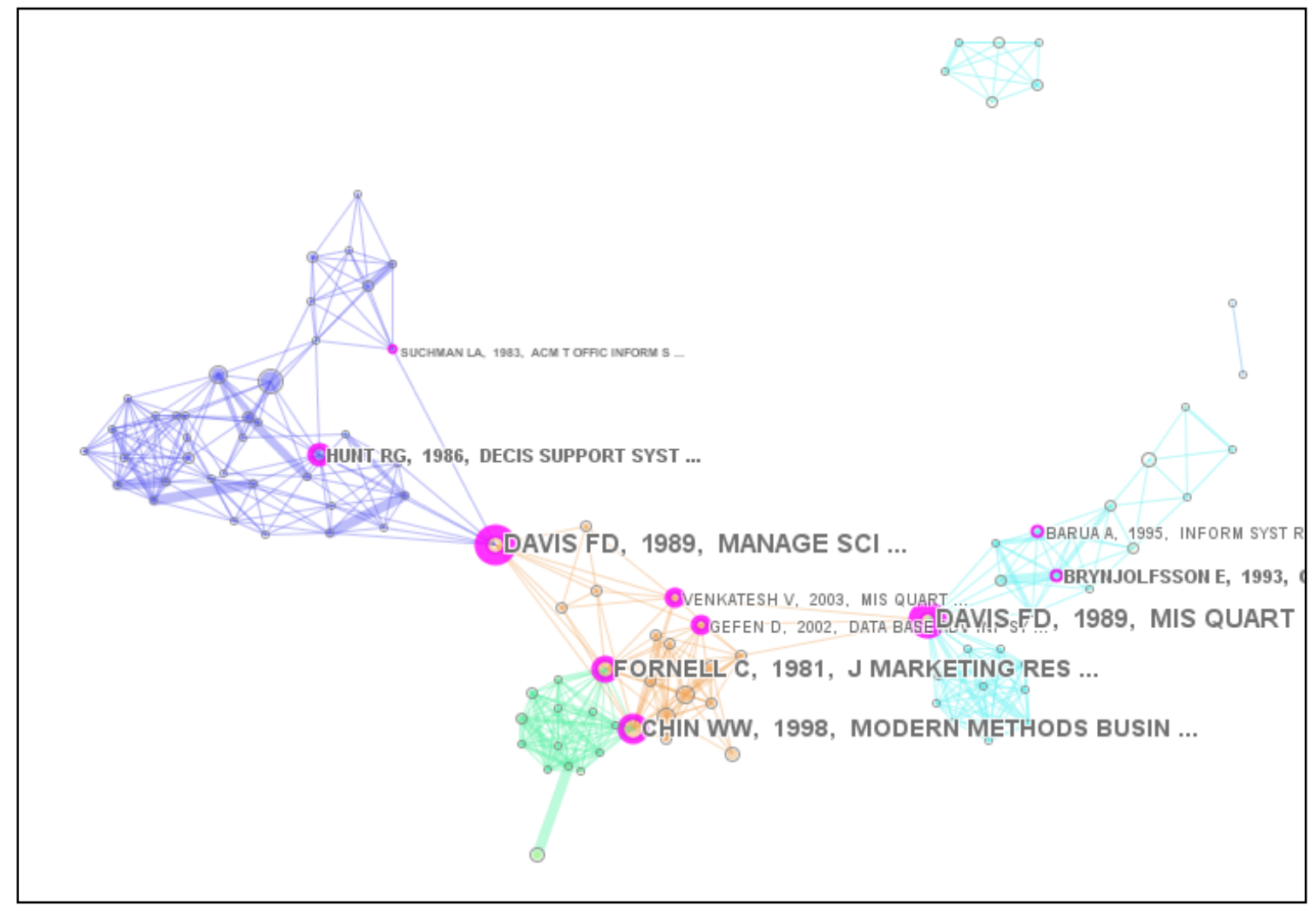

Fig. 1: CiteSpace KDViz identifying intellectually significant papers 
Table 14 Articles that are considered to be intellectually significant

\begin{tabular}{clclcc}
\hline Cit. & \multicolumn{1}{c}{ Author } & Year & \multicolumn{1}{c}{ Journal } & Vol & Start page \\
\hline 8 & DAVIS FD & 1989 & MANAGE SCI & V35 & P982 \\
8 & DAVIS FD & 1989 & MIS QUART & V13 & P319 \\
4 & HUNT RG & 1986 & DECIS SUPPORT SYST & V2 & P125 \\
3 & GEFEN D & 2002 & DATA BASE ADV INF SY & V33 & P38 \\
3 & VENKATESH V & 2003 & MIS QUART & V27 & P425 \\
7 & CHIN WW & 1998 & MODERN METHODS BUSIN & V0 & P295 \\
7 & FORNELL C & 1981 & J MARKETING RES & V18 & P39 \\
2 & SUCHMAN LA & 1983 & ACM T OFFIC INFORM S & V1 & P320 \\
3 & BARUA A & 1995 & INFORM SYST RES & V6 & P3 \\
4 & BRYNJOLFSSON E & 1993 & COMMUN ACM & V36 & P67 \\
\hline
\end{tabular}

\subsection{Articles with high citations}

The highly cited papers can be visually identified in CiteSpace. The higher the citation count for a paper, the more prominent the nodes will be in terms of their diameter. Figure 2 identifies some of the highly cited papers by ISF authors and shows its corresponding citation label. Table 15 lists the papers with five or more citations in descending order. The reader would note that a few of the articles, represented by nodes of differing sizes, are also bordered with a purple ring. This is because some of the articles not only have a high citation count (and therefore a large node size) but also they can be considered as intellectually significant (and therefore they are visually represented by a purple rim). These articles are indicated in Table 15 by a grey background.

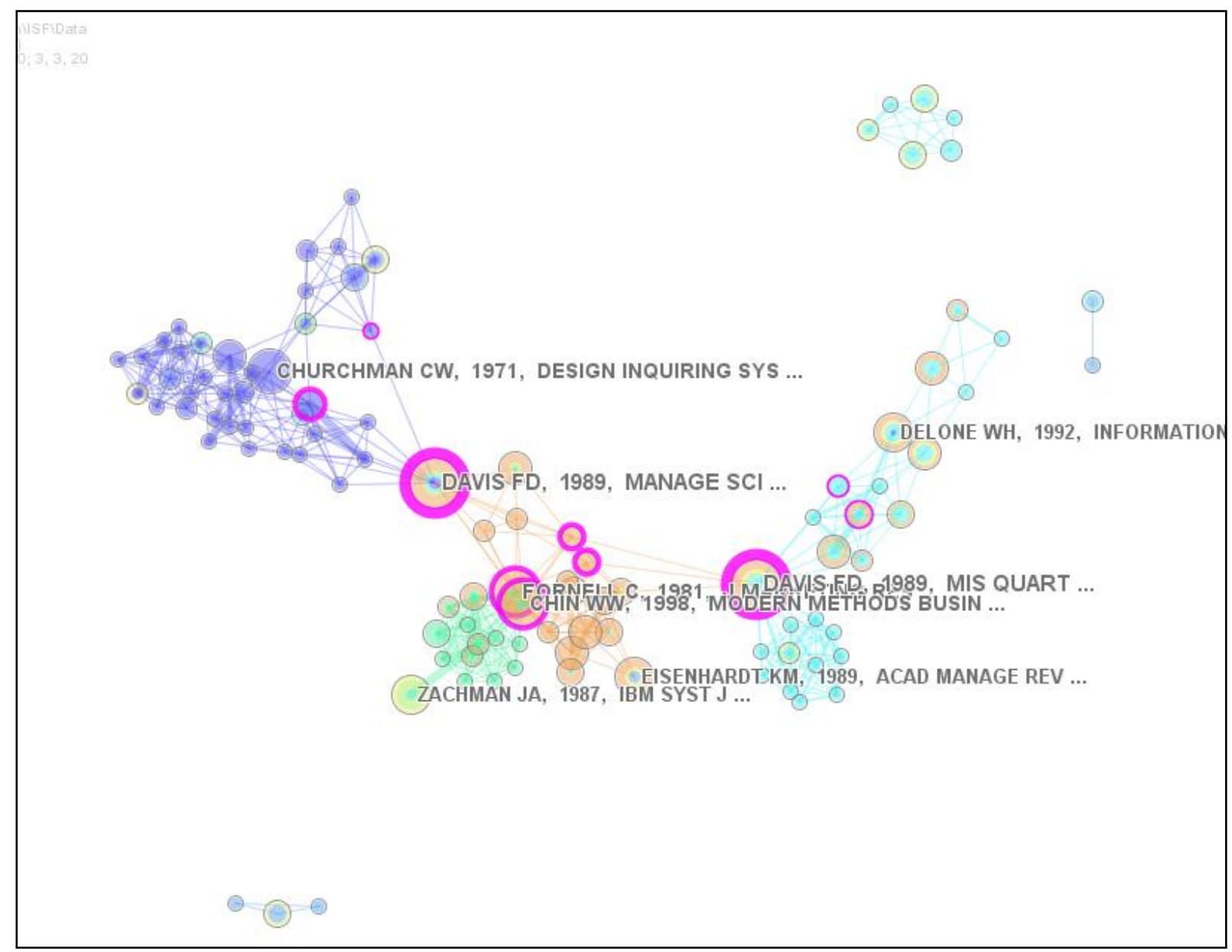

Fig. 2 CiteSpace KDViz identifying papers with a high citation count 
Table 15 Articles with high citations (>=5)

\begin{tabular}{clrlll}
\hline Cit. & \multicolumn{1}{c}{ Author } & year & \multicolumn{1}{c}{ Journal } & Vol & Start page \\
\hline 8 & DAVIS FD & 1989 & MIS QUART & V13 & P319 \\
8 & DAVIS FD & 1989 & MANAGE SCI & V35 & P982 \\
7 & CHURCHMAN CW & 1971 & DESIGN INQUIRING SYS & VBOOK & P0 \\
7 & FORNELL C & 1981 & J MARKETING RES & V18 & P39 \\
7 & CHIN WW & 1998 & MODERN METHODS BUSIN & V0 & P295 \\
6 & ZACHMAN JA & 1987 & IBM SYST J & V26 & P276 \\
6 & EISENHARDT KM & 1989 & ACAD MANAGE REV & V14 & P532 \\
6 & DELONE WH & 1992 & INFORMATION SYSTEMS & V3 & P60 \\
5 & CHURCHMAN CW & 1979 & SYSTEMS APPROACH ITS & VBOOK & P0 \\
5 & ROGERS EM & 1995 & DIFFUSION INNOVATION & VBOOK & P0 \\
5 & GROVER V & 1996 & J MANAGEMENT INFORMA & V12 & P89 \\
5 & DOSSANTOS BL & 1993 & INFORMATION SYSTEMS & V4 & P1 \\
5 & NAM K & 1996 & COMMUN ACM & V39 & P36 \\
5 & HITT LM & 1996 & MIS QUART & V20 & P121 \\
5 & DIBBERN J & 2004 & DATA BASE ADV INF SY & V35 & P6 \\
\hline
\end{tabular}

\subsection{Journals highly cited by ISF authors}

For this analysis, the Node Type cited journal has been selected. Table 16 shows the journals that have been cited most frequently by the $I S F$ authors. Only journals with 15 or more citations are listed. It is noticeable that sources that have contributed to building the intellectual wealth of ISF are the most respected outlets from both IS disciplines and its references disciplines (Business, Management, Decision Science, Computing, Economics and Organisation Science). This again indicates that $I S F$ should not be seen only as frontiers of new IS research but is truly multi-disciplinary/trans-disciplinary in nature.

Table 16 Journals with a high citation count

\begin{tabular}{clcclc}
\hline SN & \multicolumn{1}{c}{ Journal Name } & C Count & SN & \multicolumn{1}{c}{ Journal Name } & C Count \\
\hline 1 & COMMUN ACM & 86 & 12 & DECIS SUPPORT SYST & 21 \\
2 & MIS QUART & 80 & 13 & LECT NOTES COMPUT SC & 21 \\
3 & MANAGE SCI & 50 & 14 & J MARKETING & 20 \\
4 & INFORM SYST RES & 41 & 15 & INFORM MANAGE & 19 \\
5 & INFORMATION SYSTEMS & 40 & 16 & SLOAN MANAGE REV & 19 \\
6 & J MANAGEMENT INFORMA & 34 & 17 & J MANAGE INFORM SYST & 18 \\
7 & HARVARD BUS REV & 32 & 18 & ORGAN SCI & 18 \\
8 & ACAD MANAGE REV & 27 & 19 & STRATEGIC MANAGE J & 16 \\
9 & IBM SYST J & 26 & 20 & ACAD MANAGE J & 15 \\
10 & DECISION SCI & 24 & 21 & AM ECON REV & 15 \\
11 & IEEE T SOFTWARE ENG & 23 & 22 & EUR J OPER RES & 15 \\
\hline
\end{tabular}

\subsection{Use of Theory and Model}

Our exploration of $I S F$ 's publications regarding theory and models suggest that $I S F$ articles have utilised a large and diverse number of theories and models from almost all reference disciplines. The diversity of utilised theories and models is not surprising after observing the diverse range of knowledge sources that $I S F$ authors have consulted and cited in their articles (see Table 16). Although it is not possible to list all the theories and models utilised within all 307 articles of $I S F$, we are providing some examples to illustrate our point regarding the theoretical diversity of research published in ISF. These theories include: Team Theory, 
Evolutionary Game Theoretic Approach, Sitkin's Theory of Intelligent Failure, Aesthetics, Ethics, Global Ethical Management, Hegelian Inquiring System, Theory of Metaphor, Systems Theory, Singerian Model of Inquiring, Value Conflicts, Barriers to Rationality, Decision Science, Nomology, General System Theory, Freedom of Speech, Feminist Philosophy, Feminist Epistemology, Semiotics, Richness, Critical Realism, Structuration Theory, Morphogenetic Theory, Power, Coercion, Complementarism, Rational Decision Making, Self-efficacy, Performance Analytic Models, Flow Studies, Ontology, Selfintegration, Semantics, Facility Location, Strategic Multiechelon, Supply Chain Operations Reference (SCOR) Model, Quality of Service, Language-Action Perspective, Organisational Semiotics, Document Archaeology, Natural Language Processing, Theory of Object Oriented Design, Software Design Theory, Information Retrieval, Information Dynamics, Software Life Cycle Control Model, Transaction Cost Economics, Production Theory Economics, Modern Financial Theory, Change Management, Balance Theory, Game Theory, Markov Chain Model, Coordination Theory, Privacy, Business Process Management, LanguageAction Theories, Institutional Theory, Network Flow Theory, Systems Dynamics, Security Policy Domain Model, Social-Exchange Theory, Trust Theory, Belief Logic, Network Investment Economics, Resource Dependency Theory, Core Competency, Chaos Theory, Mclean Success Model, Balanced Scorecard, Organisational Learning, Cost-benefit Analysis, Business Continuity Planning, Model of Adoption of Technology in Household, Network Effect Theory, Theory of Planned Behaviour, Decomposed Theory of Planned Behaviour, Social Shaping of Technology (SST), Cognitive Theory, Diffusion of Innovations, Theory of Reasoned Action, Unified Theory of Acceptance and Usage of Technology (UTAUT), and Technology Acceptance Model (TAM).

\section{Conclusions}

This paper aimed to depict the current state of IS research published in ISF by presenting the results of a systematic and comprehensive review of 307 articles that appeared between the years 1999 and 2008. The paper presented the results of an investigation along a series of dimensions including most productive authors, research impact of most influential authors, authors' backgrounds, universities, country, region, most frequently used keywords, and methodological practice.

The following are the main conclusions that have emerged from the analysis presented in this study.

- In terms of productivity of authors, with four publications each, Amjad Umar and Michael J. Shaw have emerged as the two most productive authors of ISF.

- Authors from the male category were predominantly higher than that of the female category.

- A large proportion of ISF authors hold professorships, followed by associate and assistant professors.

- In terms of the home department of ISF authors, the largest number of researchers are from MIS/IS backgrounds, followed by Computer Science and Software Engineering.

- One of the significant observations from this study suggests that ISF authorship includes a high proportion of industry experts from renowned organisations such as IBM and HP. This indicates that the journal's audience is composed of both academics and practitioners and therefore its publications represent highly relevant and useful contributions.

- ISF publications exhibited a very strong level of collaborative works both amongst academic authors and between academic and industry experts. The largest numbers of papers are co-authored by two authors followed by three authors. There are a number of articles jointly co-authored by five, six, seven and ten authors. 
- The universities with the largest number of contributions (seven contributors from each) are the Arizona State University and Claremont Graduate University, both of which are based in the United States. The top 17 list also includes a number of universities from outside USA, for example: Brunel University from UK, University of Twente from The Netherlands, University of Waterloo from Canada and the City University of Hong Kong from the Asia region.

- It is also interesting to note that two commercial organisations (IBM and Telcordia Technologies Inc.,) also appeared within the list of most productive institutions.

- USA is the single largest contributor of $I S F$ authors and their institutions. Consecutively, AIS-R1- USA and Canada emerged as the most dominant region, followed by AIS-R2Europe and UK.

- The analytical/descriptive/theoretical/conceptual methods were the most dominant research approaches utilised by $I S F$ authors within the 10 years studied, followed by case study, experiment and survey.

- A keywords analysis indicated that 'systems', 'model', 'technology', 'performance' and 'management' were the most utilised and turning point keywords, or in other words, the most investigated research issues.

- The highest research impact is reported for the paper published by Ross and Vitale (2000) followed by Stohr and Zhao (2001), which was assessed by citations obtained from Google Scholar for all articles published in ISF.

- There are a number of studies published in other journals that have had a great influence on the work of $I S F$ authors as they frequently cited them. These include Davis (1989) and Davis et. Al. (1989).

- Literature sources that $I S F$ authors frequently refer to consist of high-quality and respected IS and Management journals including Communications of ACM, MIS Quarterly, Management Science, Information Systems Research, Journal of Management Information Systems, Harvard Business Review and IBM Systems Journal. This makes it clear that ISF's intellectual wealth has been built upon very strong foundations, which reflects well on its own quality and recognition.

- By considering the theoretical and methodological richness in ISF's articles and the relevance and usefulness of its publications for both academia and industry, it would not be inappropriate to conclude that the journal's approach is in a true sense multidisciplinary in nature drawing from fields such as computer science, telecommunications, operations research, economics, cognitive sciences, object/web technologies, information economics, IT integrated manufacturing, medical informatics, digital libraries, mobile computing, and electronic commerce.

- Finally, the data presented within this paper clearly indicates that ISF provides a common forum for both frontline industrial developments as well as pioneering academic research.

We anticipate that this paper will prove to be a useful source of information for ISF readers who wish to learn more about the various facets pertaining to the existing body of published IS research in $I S F$.

\section{Reference:}

Adam, A., \& Richardson, H. (2001). Feminist philosophy and information systems. Information Systems Frontiers, 3(2), 143-154.

Arrow K.J. (2003) Foreword: Information Dynamics in the Networked World, Information Systems Frontiers, 5: 1, 5.

Arrow K.J. (1999) Team Theory and Distributed Processing: Surprise Attack, 
Information Systems Frontiers, 1: 1, 11-14.

Avison, D., Dwivedi, Y. K., Fitzgerald, G., \& Powell, P., (2008). The beginnings of a new Era: Time to reflect on 17 years of the ISJ. Information Systems Journal, 18 (1), 5-21.

Barki, H., Rivard, S., \& Talbot, J. (1993). A keyword classification scheme for IS research literature: an update. MIS Quarterly, 17 (2), 209-225.

Bell, D., de Cesare, S., Iacovelli, N., Lycett, M., \& Merico, A. (2007). A framework for deriving semantic web services. Information Systems Frontiers, 9(1), 69-84.

Bunker, D. (2001). A philosophy of Information Technology and Systems (IT \& S) as tools: Tool development context, associated skills and the Global Technology Transfer (GTT) process. Information Systems Frontiers, 3(2), 185-197.

Chen, C. (2004). Searching for intellectual turning points: Progressive knowledge domain visualization. Proceedings of the National Academy of Sciences, USA, 101 (Suppl.), 5303-5310.

Chen, C. (2006). CiteSpace II: Detecting and visualizing emerging trends and transient patterns in scientific literature. Journal of the American Society for Information Science and Technology, 57(3), 359-377.

Chen, W.S. \& Hirschheim, R. (2004). A paradigmatic and methodological examination of information systems research from 1991 to 2001. Information Systems Journal 14 (3), $197-235$.

CiteSpace Wiki. (2008). CiteSpace Glossary. https://cluster.cis.drexel.edu:8443/cswiki/index.php/Glossary. Last accessed August 21, 2008.

Clarke, R. (2008). An Exploratory study of information systems researcher impact. Communications of the Association for Information Systems 22, 1-32.

Claver, E., Gonzalez, R., \& Llopis, J. (2000). An analysis of research in information systems (1981-1997). Information \& Management 37, 181-195.

Davis, G. B. (1999). A Research for Information Systems and Example of Emerging Area of Research. Information Systems Frontiers, 1(3), 195-203.

Davis, F. D. (1989). Perceived usefulness, perceived ease of use, and user acceptance of information technology. MIS Quarterly 13, 319-340.

Davis, F. D., Bagozzi, R. P. and Warshaw P. R. (1989). User acceptance of computer technology: a comparison of two theoretical models. Management Science 35 (8), 982-1003.

Dobson, P. J. (2001). The philosophy of critical realism - An opportunity for information systems research. Information Systems Frontiers, 3(2), 199-210.

Dwivedi, Y. K., \& Kuljis, J. (2008). Profile of IS research published in the European Journal of Information Systems. European Journal of Information Systems 17 (6), (forthcoming)

Dwivedi, Y.K., Kiang, M., Lal, B., \& Williams, M.D. (2008). Profiling Research Published in the Journal of Electronic Commerce Research. Journal of Electronic Commerce Research, 9 (2), 77-91.

Dwivedi, Y.K., Williams, M.D., \& Venkatesh, V. (2008a). Guest Editorial: A profile of adoption of Information \& Communication Technologies (ICT) research in the household context. Information Systems Frontiers, 10(4), 385-390.

Freeman, L. A. (2001). Information Systems Knowledge: Foundations, Definitions and Applications. Information Systems Frontiers, 3 (2), 249-266.

Gray P., \& Hovav A. (1999). Using Scenarios to Understand the Frontiers of IS. Information Systems Frontiers, 1(1), 15-24.

Gregg, D. G., Kulkarni, U. R., \& Vinze, A. S. (2001). Understanding the philosophical underpinnings of software engineering research in Information Systems. Information Systems Frontiers, 3(2), 169-183.

Palvia, P., Pinjani, P., \& Sibley, E.H. (2007). A profile of information systems research published in the Information \& Management. Information \& Management, 44, 1-11.

Ramesh, R., \& Rao, H.R. (2008). Editorial. Information Systems Frontiers, 10(1), 1-2. 
Ross, J.W., \& Vitale, M.R. (2000). The ERP Revolution: Surviving vs. Thriving. Information Systems Frontiers, 2 (2), 233-241

Sage A.P., \& Rouse W.B. (1999). Information Systems Frontiers in Knowledge Management. Information Systems Frontiers, 1(3), 205-219.

Shaw M.J. (1999). Electronic Commerce: Review of Critical Research Issues. Information Systems Frontiers, 1(1), 95-106.

Stohr, E. A., \& Zhao, J. L. (2001b). Workflow automation: Overview and research issues. Information Systems Frontiers, 3(3), 281-296.

\section{Authors Biography}

Yogesh K. Dwivedi is a Lecturer in Information Systems at the School of Business and Economics, Swansea University, Wales, UK. He obtained his $\mathrm{PhD}$ entitled 'Investigating consumer adoption, usage and impact of broadband: UK households' and MSc in Information Systems from the School of Information Systems, Computing and Mathematics, Brunel University, UK. His doctoral research has been awarded the 'Highly Commended Award' by the European Foundation for Management and Development (EFMD) and Emerald Group Publishing Ltd. His research focuses on the adoption and diffusion of Information and Communication Technology (ICT) in organisations and society. As well as having presented at leading IS conferences such as ECIS and AMCIS, he has co-authored several papers which have appeared (or will be appearing) in international referred journals such as Communications of the ACM, Information Systems Journal, European Journal of Information Systems, Information Systems Frontiers, Journal of Operational Research Society, Journal of Computer Information Systems, Industrial Management \& Data Systems and Electronic Government, An International Journal. He has authored a book on 'Consumer Adoption and Use of Broadband' and also co-edited a 'Handbook of Research on Global Diffusion of Broadband Data Transmission'. He is Senior Editor of DATABASE for Advances in Information Systems, Assistant Editor of Transforming Government: People, Process and Policy and member of the editorial board/review board of several journals including Journal of Enterprise Information Management, Journal of Computer Information Systems, Electronic Government, An International Journal as well as being a guest/issue co-editor of the DATABASE for Advances in Information Systems, Government Information Quarterly, Information Systems Frontiers, Journal of Enterprise Information Management, Journal of Electronic Commerce Research and Electronic Government, An International Journal. He is a member of the Association of Information Systems (AIS), IFIP WG8.6 and the Global Institute of Flexible Systems Management, New Delhi. $\mathrm{He}$ can be reached at ykdwivedi@gmail.com.

Banita Lal is a lecturer in the Nottingham Business School, Nottingham Trent University, UK. She obtained her Ph.D. and M.Sc. in Information Systems from the School of Information Systems, Computing and Mathematics, Brunel University. Her research interests involve examining the individual and organizational adoption and usage of ICTs and technology-enabled alternative forms of working. She has published several research papers in internationally refereed journals such as Industrial Management and Data Systems, Information Systems Frontiers, Electronic Government, International Journal of Mobile Communications, and Transforming Government: People, Process and Policy, and has presented several papers at several international conferences. She can be reached at banita.la.@ntu.ac.uk

Navonil Mustafee is a research fellow in Warwick Business School. His research interests are in parallel and distributed simulation, grid computing and health care simulation. He completed his PhD in Information Systems and Computing Brunel University in 2007. He is a member of the drafting group of the COTS Simulation Package Interoperability Product Development Group (CSPI-PDG) under the Simulation Interoperability Standards Organization. He can be reached at navonil.mustafee@gmail.com 
Michael D. Williams is a Professor in the School of Business and Economics at Swansea University in the UK. He holds a BSc from the CNAA, an MEd from the University of Cambridge, and a PhD from the University of Sheffield. He is a member of the British Computer Society and is registered as a Chartered Engineer. Prior to entering academia Professor Williams spent twelve years developing and implementing ICT systems in both public and private sectors in a variety of domains including finance, telecommunications, manufacturing, and local government, and since entering academia, has acted as consultant for both public and private organizations. He is the author of numerous fully refereed and invited papers within the ICT domain, has editorial board membership of a number of academic journals, and has obtained external research funding from sources including the European Union, the Nuffield Foundation, and the Welsh Assembly Government. He can be reached at m.d.williams@swansea.ac.uk 